\title{
The Effect of Social Status and Size of Imposition on the Gratitude Strategies of Persian and English Speakers
}

\author{
Vajiheh Ahar \\ Isfahan University, Iran \\ Email: gh.ahar@yahoo.com \\ Abbas Eslami-Rasekh \\ Isfahan University, Iran
}

\begin{abstract}
This study investigates the strategies Native English and Persian speakers employ for expressing gratitude in different situations. The strategies of Persian EFL learners are also compared with English strategies in order to find the differences that may exist between these two languages. Social status and size of imposition of the favor are social variables which are investigated in detail for three groups. Researchers working in second language (L2) acquisition have investigated interlanguage pragmatics (ILP) to document learners' formulation of speech acts (SAs) and they have found that most of the problems that EFL learners face in intercultural communication are mainly pragmatic (Blum-Kulka, House, Kasper, 1989; Kasper, 1989;Kasper, 1992; Cohen, 1996; Al Falasi, 2007; Eslami-Rasekh \& Eslami-Rasekh, 2004). Unlike comprehensive studies on SAs such as request and apology, the number of cross-cultural studies investigating expressions of gratitude is fairly limited and there are few studies investigating this speech act in Persian. The participants of this study were 75 advanced students from the English department of Isfahan University. The participants were both male and female, aging from 20 to 31 years old. 24 American college aged, native speakers also participated in this study. An open-ended DCT were employed for studying participants' responses and verbal reactions to different situations. The results of Chi-square test suggested that Persian and English speakers vary in their gratitude strategies. Persian students' sensitivity to social variables made them use inappropriate expressions and strategies in their English responses. It suggested that Persian learners of English transfer some of their L1 pragmatic norms to L2 because they perceive these norms to be universal.
\end{abstract}

Index Terms - contrastive pragmatics, interlanguage pragmatics, speech act, gratitude strategies

\section{INTRODUCTION}

Persian and English native speakers give thanks and reply to thanks on numerous occasions in their everyday-life interactions with family members, friends, acquaintances and strangers. It is necessary to learn how to understand and produce language that is appropriate to the situations in which one is functioning, because failure to do so may cause misunderstandings and miscommunications. Being able to express one's gratitude and respond to expressions of gratitude appropriately in a wide variety of situations ranging from thanking someone for opening a door to expressing one's gratitude for a gift is something that most native speakers (NSs) take for granted.

NSs can draw on the resources of their linguistic and sociocultural knowledge to formulate their speech appropriately for a given context. This knowledge is referred to as pragmatic competence. However, as Bodman and Eisenstein (1988) point out "learners of a foreign language often assume that the expression of gratitude is universal and remain unaware of significant differences in its cross-cultural realization" (p. 1). As a result, neither native speakers nor learners of the target language expect to encounter different strategies in the thanking behaviour in their interactions with each other.

In the area of cross-cultural study of speech acts, researchers have focused on how a particular speech act is linguistically realized in different languages. It is assumed that if speakers of two languages differ in the way they perform the same speech act, then it is predictable that learners of a second language may develop a particular interlanguage for doing that act. Contrastive pragmatic studies like the current work determine the patterns and strategies that native speakers of one language use in different situations. By comparing the patterns of expressing one SA in two languages teachers can equip their students with necessary and appropriate tools for successful communication. Pragmatics has typically been ignored by textbooks and teacher training programs, especially in Iran, and despite the wealth of empirical studies conducted on speech acts in general, few data-based studies have focused on L1 transfer of gratitude expressions.

\section{LITERATURE REVIEW}

Study of pragmatic development in a second language or interlanguage pragmatics (ILP) as the study of a second 
language use, examines how non native speakers comprehend and produce action in the target language and investigates how L2 learners develop the ability to understand and perform action in a target language . Yet they have similarly drawn a universal conclusion that nonnative speech act behaviors can deviate from native behaviors. (Blum-Kulka \& Olshtain, 1984; Faerch \& Kasper, 1987; Murphy \& Neu, 1996; Olshtain, 1989; Olshtain \& Cohen, 1983; Olshtain \& Blum-Kulka, 1985, 1989; Yu,1999).

Al Falasi (2007) believes that most of the problems that EFL learners face in intercultural communication are mainly pragmatic. Teachers of EFL often choose not to stress pragmatic knowledge in their classrooms, focusing instead on linguistic knowledge. Eslami-Rasekh \& Eslami-Rasekh (2004) warn that this might result in pragmatic failure when EFL learners actually communicate with native speakers (NSs) and the only way to minimize pragmatic failure between NSs and NNSs is by acquiring pragmatic competence, that is, the ability to use language effectively in order to understand language in context.

One of the SAs and important discourse functions that learners are likely to encounter in a variety of situations are expressions of gratitude (Coulmas, 1981). The SA of thanking is an expressive act in the classifications of Searle (1976) This act is reactive to the prior actions of the interlocutor. Based on different social variables and also the size of favour the thanking expressions are accompanied by additional acts that directly address the actions of the hearer by way of compliments, expressing indebtedness, and stating the speaker's inability to articulate deep feelings, e. g. You're a lifesaver. Thanks. I'll never forget it. You really can't imagine what this means to me.

Apte's (1974) study is one of the earliest investigations of expressions of gratitude. He compared giving thanks in Marathi and Hindi to expressing gratitude in American English and found that " the usage of gratitude expressions in American culture is much more extensive than in South Asian communities" (p. 84). While in American English giving thanks for favours, gifts or services is considered appropriate and expected, for Marathi and Hindi expressing gratitude to family members or close friends for favours violates the feeling of closeness, as it is the duty of family members and close friends to help each other.

Eisenstein and Bodman (Eisenstein \& Bodman, 1986, Bodman \& Eisenstein 1988) compared the use of expressions of gratitude by groups of participants with different language backgrounds and American English native speakers. They found that while certain language groups performed better than others, e.g. the results of the Russian speakers were better than those of the Japanese speakers, "the problems exhibited by [their] non-native speakers were extensive and severe" (1986, p. 173).

Ohashi's (2000) PhD thesis reveals that Japanese thanking is not the expression of gratitude or appreciation but a symbolic repayment of debt with which the beneficiary redresses the debt-credit imbalance. This result is in line with Miyake (1994) Nakata, (1989), Nakai and Watanabe (2000). Nakamura (2005) comparing English and Japanese thanks noted that while American English native speakers tended to use more compliments when expressing gratitude than Japanese native speakers, Japanese native speakers employed more apologetic expressions.

Janani, on the other hand, investigates the effect of levels of proficiency on gratitude expressions of Persian EFL learners. He claims that the difference between two levels of students was not meaningfully significant. Ghobadi and Fahim (2009), based on the obtained data from the explicit instruction group, indicated that instruction had an impressively positive effect on raising students' sociopragmatic awareness as well as their hindrance of L1 pragmalinguistic transfer to L2.

\section{METHODOLOGY}

\section{A. Participants}

Two groups of subjects participated in this study and these subjects were confined to undergraduate and graduate students. The PNS group had 75 native speakers of Persian at the University of Isfahan and the ANS group also consisted of 24 American college-aged, native speakers. These participants were both male and female, aging from 20 to 31 .

\section{B. Instrument}

The instruments used in this study were Nelson English language proficiency test and Discourse Completion Test (DCT). Nelson test included 50 multiple choice items covering grammar, vocabulary, and reading comprehension. There were two pragmatically equivalent versions of the questionnaire, one in English and the other one in Persian. The English version was designed first and then was rendered in Persian. The two versions of English and Persian questionnaire were first given to some native Persian and English speakers to make sure that these devices elicit the desired responses. These ten situations were then given to the students and were used as a basis for comparison.

\section{Procedures}

First, the advanced test of Nelson was administrated to our 134 participants, and mean (M) and standard deviation (SD) of their scores were calculated. The mean score was 30.38 and the standard deviation was 5.31. The subjects whose scores fell between $0.5 \mathrm{SD}$ (2.65) above the M were considered as high level learners. 75 students were selected for the main study. These 10 situations were designed to reflect combinations of different degrees of power and size of imposition. As power difference could imply differences in both age and status, the addressees in the situations were 
designed to be equal or higher in both age and status compared to undergraduate and graduate students. Regarding the social distance between the interlocutors, in this work participants were to interact with people who were familiar with and it can be said that social distance was kept as a controlled variable.

As far as the size of imposition was concerned the big favour indicated either hard work requiring considerable time and/or financial/physical burden for the hearer, or the size of the benefit that the speaker received from the hearer of the conversation; e.g. the favor of a friend who offers $500.00 \$$ loan to the speaker was considered as a big favor, while giving back the speaker's pen was of fairly low level of imposition, since a small favor involved only momentary actions or an insignificant expense. Persian EFL students were required to answer both the English and the Persian versions of the questionnaire so as to see how they express their gratitude in these situations in their first language and their foreign language. The questionnaire was given to 24 native English speakers in order that it would be possible to compare Persian students' responses with those of native English speakers.

\section{Data Analysis}

The data collected for this study were analyzed according to the two major contextual factors, namely, the size of imposition or magnitude of the favor and social status. And in each analysis three groups of responses, Persian (L1), English (L1) and English as the foreign (L2) were examined. A detailed description of the ten scenarios in relation to the combination of the two factors i.e. size of imposition and social status is presented in Table 2. (The number of situations in the table is different from the number of the items in the DCT)

TABLE 1.

THE DISTRIBUTION OF CONTEXTUAL FACTORS

\begin{tabular}{|l|l|l|l|}
\hline Gratitude strategies & $\begin{array}{l}\text { Native } \\
\text { American }\end{array}$ & $\begin{array}{l}\text { Persian } \\
\text { EFL }\end{array}$ & $\begin{array}{l}\text { Native } \\
\text { Persian }\end{array}$ \\
\hline Simple thanking & $70 \%$ & $57 \%$ & $37.60 \%$ \\
\hline Acknowledging the favor & $2 \%$ & $15 \%$ & $22 \%$ \\
\hline Complimenting the person/action & $15 \%$ & $2.85 \%$ & $0.9 \%$ \\
\hline Apologizing & $0 \%$ & $12.45 \%$ & $18.98 \%$ \\
\hline Asking God for rewarding the person/a good wish & $2 \%$ & $6.95 \%$ & $15.38 \%$ \\
\hline promising compensation & $11 \%$ & $5.71 \%$ & $5.12 \%$ \\
\hline Total & 100 & 100 & 100 \\
\hline
\end{tabular}

TABLE 2.

FREQUENCY OF GRATITUDE STRATEGIES IN THREE GROUPS OF RESPONSES

\begin{tabular}{|l|l|l|l|}
\hline \multirow{2}{*}{ Situation } & Brief description & \multicolumn{2}{|l|}{ Contextual factors } \\
\cline { 3 - 4 } & & Size of imposition & Social status \\
\hline 1 & Fixing the computer & + & $=$ \\
\hline 2 & 500 \$ loan & + & $=$ \\
\hline 3 & Cleaning your face & - & $=$ \\
\hline 4 & Finding your pen & - & + \\
\hline 5 & Salary raise & + & + \\
\hline 6 & Recommendation letter & + & + \\
\hline 7 & Answering a question & - & + \\
\hline 8 & Keeping the door open & - & - \\
\hline 9 & Helping with luggage & + & - \\
\hline 10 & Bringing coffee & - & \\
\hline
\end{tabular}

\section{RESULTS AND DISCUSSION}

The DCT used in this study contains ten scenarios, four scenarios involve higher social status of the addressee, four involve equal social status of the interlocutors, and two situations involve lower social status of the addressee. In each group of the situations related to a special social status, half involve a high size of imposition and the other half involve a low size of imposition. For instance the four items that represent higher social status include two situations for favors with a significant size of imposition and two situations for a relatively small size of imposition, in order that the effect of this social variable regarding different sizes of favors can be investigated.

\section{A. Higher Social Status}

\section{a. Persian speakers}

Considering the four items involving an interlocutor with a higher social status $(3,4,8 \& 9)$, Persian speakers produced different strategies, with respect to the kind and size of the favor. For the third scenario the most common strategy was using motshakeram (Thank you) as a simple expression of gratitude and adding another strategy such as acknowledging the favor. A typical answer to this situation was:

1- Motshaker-am. Kheili lotf kard-id. Thank you. Very favor did-2nd Pl. Thank you. You did a great favor.

The participants produced some other creative responses too. For example some of them stated their happiness because of the boss's satisfaction of their work:

2- Motshaker-am. Khoshhal-am ke az kar-am razi hast-id. Thank you. Happy-1st sing that from work-my satisfied 
are-2nd Pl Thank you. I'm happy that you are satisfied with my work.

The responses to the professor (situation 4) were more diverse. Most of the speakers felt more intimacy with the professor and used other simple thanking strategies like mamnun and mersi (thank you) beside the more formal expression of motshakeram. They also considered it necessary to appreciate the Professor because of the allotted time:

3- Kheili lotf kard-id, Doctor. Bebakhsh-id vaqt-e-tun-o gereft-am.

Very favor did-2nd Pl, Doctor. Subj-forgive-2nd pl time-your-obj marker took-1st sing You made a great favor, Doctor. I'm sorry that I took your time.

4- Mamnun ostad. In lotf-etun-o faramush nemikon-am. Thanks Professor. This favor-your-obj marker forget don't-1st sing Thanks professor. I don't forget your favor.

Examining the other two scenarios ( $8 \& 9$ ) which involved relatively small favors our participants employed the following strategies:

Persian speakers thanked their professors because of answering their question and keeping the door open for them, by using simple thanking strategy in addition to using the titles:

5- Mamnun ostad. Lotf kard-id. Thanks professor. Favor did-2nd Pl Thanks professor. You made a favour.

6- Sharmande ostad. Ashamed professor I'm ashamed professor.

7- Dast-e-tun dard na-kone. Mamnun Hand-your-Pl pain Neg-marker-do. Thanks May your hand never ache. Thanks.

Here the responses were kept relatively short because of the size of favor and due to the fact that the speakers didn't have much time and in the scenario of keeping the door open, both of the interlocutors were passing through the door. The Persian speakers used at most two expressions of gratitude in these situations.

One interesting point is that in all of the four situations that speakers are encountered with someone of higher social status, Persian participants used plural pronouns as signs of respect for the superior interlocutor, either in the form of independent pronouns or in the form of verbal endings.

For instance:

8- Lotf kard-i. (friend) Favour did-2nd sing You did a favor.

9- Lotf kard-id/kard-in. (professor/boss) Favour did-2nd Pl You did a favor.

10- Dast-et dard nakone. (friend) Hand-your sing pain doesn't May your hand never ache.

11- Dast-e-tun dard nakone. (professor/boss) Hand-your Pl pain doesn't May your hand never ache.

b. Persian learners of English

Persian learners of English expressed their gratitude in these situations with limited variation and kept their utterances relatively short. Many learners tried to add intensifiers to reach the desired level of appropriateness for these big favors. For instance they produced the following utterances:

12- I really do appreciate it sir.

13- That's a kind of you, thank you very much indeed.

14- Thanks sir that's very kind of you.

15- I'm extremely grateful to you for your kindness.

For the third situation (the boss) there were learners, however, who thanked God because their work had been satisfactory and recognized:

16- Thanks God you're pleased with my job.

Besides the strategy of simple thanking, with various wordings, few learners used a complimenting strategy to appreciate the professor. This pattern was not observed in the case of the boss, however.

17- Thanks a lot you are such a humble and praiseworthy teacher, thanks.

English learners resorted to different strategies for handling situation 8 and 9 . These learners used simple thanking and sometimes added titles:

18- Thanks a lot

19- Thank you sir

20- Thanks for your kindness

21- That's very kind of you. Thanks.

22- Thanks sir that's very kind of you.

More creative responses included expressing thanks in addition to wishing something good for the hearer:

23- Thank you very much. Have a nice day.

and, of course, expressing apology:

24- I'm sorry. Thanks.

25- Thanks sir. You really made me ashamed.

c. American speakers

Looking at the Americans common strategies for these two situations it became evident that they didn't use any especial strategy and as our data in the previous section showed they resorted to simple thanking as the dominant pattern $(70 \%)$.

26- thank you very much

27- Thank you. Thank you so much.

In the third scenario some American students expressed their pleasure and happiness of the attention that had been 
paid to their work. It seemed that compared with Persian students, they did not think that it was merely the favor of the company president; rather, raising the salary was considered to be one's own achievement:

28- I'm glad to work for a company that recognizes my work.

29- I am happy that you paid attention to my work. Thank you.

One important difference in these situations between American and Persian students seemed to be the use of titles in addressing, with gratitude expressions. For example many Persian speakers used titles like ostad, doctor, agha, jenabe raeis, etc. in Persian and professor, Doctor, Sir, Mr. Boss, etc. in their English interlanguage performance language, respectively.

Nearly all American speakers, however, employed one expression of gratitude in the situations that represented small sizes of imposition on the speaker. Simple thanking, and more specifically, thank you, was the strategy that these participants considered most appropriate for these scenarios:

30- Thank you very much.

31- Thank you.

32- Thanks.

One interesting point observed was that generally in all of these situations, involving both big and small favors, participants tried to keep their utterances relatively short and brief. This result is in line with Eisenstein and Bodman's findings (1986) and confirms one aspect of Wolfson's Bulge Theory (1989), identifying brevity in communications between socially distant interlocutors.

\section{B. Equal Social Status}

Whenever our participants were encountered with someone who had the same social status as them, they produced various and creative speech act sets depending on the kind and size of the favor. The first two scenarios of the questionnaire represented situations in which a classmate or a friend try to solve a problem for the speaker and the speakers felt greatly indebted to them.

In the first scenario the speaker had some problem with a computer program and asked a classmate to help him/her. The classmate managed to solve the problem and showed how to avoid the problem in the future. In the next scenario the speaker needed 500.00\$ and his/her friend offered to lend the money.

Scenarios 6 and 7 represent real life situations in which a friend does a relatively small favor to his/her friend. As mentioned before, small favor involves only momentary actions or favors with insignificant expense. For instance in the sixth scenario at the table in a restaurant a friend says, 'You have something on your face.' In the seventh scenario one of your classmates finds your pen, puts it into his/her bag and gives it back to you the following day before a seminar. Compared to the last two items which referred to big favors, here the speakers employed a limited range of strategies.

a. Persian speakers

Persian participants used different strategies of gratitude for each situation. All speakers used simple thanking at the beginning, middle or last of the sentence. Thanking was accompanied by acknowledging the favour, asking God for rewarding the favourer/wishing s.th good, apologizing, promising compensation and complimenting the favourer:

33- Vay mersi, kheili lotf kard-i. I-sha-la jobran kon-am.

Oh thanks, very favour did-2nd sing.if-wants-God compensation do-1st sing Oh thanks, you did a great favour. If God is willing I'll compensate.

34- Khoda kheir-et bede. Kheili komak-am kard-i, mamnun.

God blessing- to you subj-give-3rd sing. Very help-me did-2nd sing, thanks God bless you. You helped me very much. Thanks.

35- Mersi pesar. Vaqean sharmand-am kard-i

Thanks boy. Really ashamed-me did-2nd sing Thanks boy. You really made me ashamed.

In the case of lending the money, Persian participants employed the same strategies and produced similar responses. The only significant difference was using the strategy of promising compensation. Many speakers considered it necessary to mention the kind or exact time of repayment. These statements can be considered supporting acts that are added to the head acts of thanking. For example they stated that:

36- Vay sharmande, nemidunam chejuri azat tashokor konam. Jobran mikonam. Oh ashamed, don't know-1st sing how-kind from-you thank do-1st sing. compensation do-1st sing. Oh I'm ashamed, I don't know how to thank you. I'll compensate.

37- Mersi kheili lotf kardi, ta akhar-e hafte pul-et-o barmigardunam.

Thanks very favor did-2nd sing, by end-of week money-your-obj marker payback- 1st sing Thanks you did a great favor, by the end of the week I'll payback your money.

When a friend brought attention to something on the speaker' face, Persian participants usually asked if their face had been cleaned and then simply thanked their friends:

38- Pak shod? Mersi Clean became-3rd sing? Thanks Is it removed? Thanks.

Many students just used mersi and mamnun (thanks) and since they had been given the choice to opt out a situation if they think no appreciation is needed, some of the participants didn't use any thanking expression.

The favor of the classmate that gave the pen back was more acknowledged by our Persian participants than bringing attention to something on the face. In addition to simple thanking strategy, mersi and mamnun (thanks), Persian 
speakers employed acknowledging the favor:

39- Mamnun, lotf kard-i. Thanks, favor did-2nd sing Thanks, you did a favor.

40- Xeili lotf kard-i, mersi. Very favor did-2nd sing, thanks You did a great favor, thanks.

Asking God for rewarding the person/a good wish was also used in the form of:

41- Dast-et dard nakone. Hand-your sing pain doesn't May your hand never ache.

For this scenario Persian speakers used another strategy that was not used in any other situation of our questionnaire.

Considering the value and the price of the pen, some speakers referred to the value of their interlocutors and tried to raise their worth by lowering the value of the pen.

42- Qabel-i na-dasht. orth-any Neg-marker-had It (pen) didn't worth. Or

43- Qabele to ro na-dasht. Worth-of you obj-marker Neg-marker-had It didn't worth you.

On the other hand the speakers indirectly offer their pen and imply that the hearer could keep it for him/herself.

Accordingly, this semantic formula can be considered a strategy of ostensible speech act.

b. Persian learners of English

Persian learners of English produced similar strategies in their English responses to these items. After the strategy of simple thanking, acknowledging the favor was the most frequent strategy for these two scenarios:

44- Thank you very much. You really helped me I don't know how to appreciate you.

45- Thank you an ocean, you were a great help to me.

46- Oh that is great. It's your favor, thanks.

As might be expected, apologizing was used by many learners for expressing gratitude:

47- Thank you very much. I'm really sorry that I got you in trouble.

48- Thank you an ocean. You made me shy.

49- Sorry dear, you really helped me. Thank you very much.

50- That is very nice of you; I didn't want you to get in trouble.

When responding in English, nearly all Persian participants employed simple thanking for both of these situations. One of the differences in strategy use between these two situations was adding different intensifiers to the responses of the seventh scenario.

51- Thank you very much.

52- Thanks a lot.

53- Thank you very much indeed.

c. American speakers

American university students appreciated their interlocutors with different ways of simple thanking. For the first scenario, they preferred complementing their interlocutors and giving some titles to the other strategies:

54- Thanks for your help, you are a life saver.

55- You are a genuine miracle worker.

56- You are a computer God.

57- Dude you are a life saver. Thanks

58- You computer geek!

59- Hey bro, thanks for fixin up my suit.

There were, however, other speakers who combined various strategies and produced longer responses, for example:

60- Dude you are a life saver. Thanks so much for fixing my computer and saving me thousands of dollars.

61- Thanks, you have no idea how much this is appreciated.

62- Thanks a lot. I'd never have worked it out on my own.

63- I appreciate your skill, you are a computer God.

In the case of lending the money, after simple thanking, promising compensation was used by many speakers and stating one's intent to reciprocate appeared to be much more standardized:

64- Thank you. If there is anything I can ever do to repay you just let me know.

$65-$ You dog! If you need somethin' just holla at me.

American speakers usually asked questions to make sure that their friend is completely willing to lend the money and it is no problem to them. For instance many participants before accepting the check asked:

66- Are you sure? Great, thanks.

67- Really? You are sure? Ok, thanks.

68- You don't mind? Thanks very much.

American speakers used simple thanking for these situations as well and it seemed that for these situations the responses of Native Americans and Persian learners of English were quit similar. The only observed difference was using expressions like cheers and ta by a number of American respondents.

\section{Lower Social Status}

\section{a. Persian speakers}

The DCT questionnaire used in this study contained two situations in which the speakers wanted to communicate with someone of lower social status. In order to control the effect of age for people of lower social position, in these scenarios speakers were to interact with people who are younger and possess a lower social status. In many cultures 
such as Persian culture elder people are treated politely and respectably, no matter what social status they may have.

Accordingly there were two situations $(5 \& 10)$ that speakers were faced with younger interlocutors from a lower social status. In the fifth situation that tended to reflect a big favor our participant was coming back from a trip and his/her neighbor's son helps him/her with luggage and bags and brings them to the speakers flat. In the tenth scenario a student that the participant tutored brought him/her coffee. This scenario was placed in the DCT in order to represent a relatively small and expected favor.

Persian speakers used mersi (thanks) besides other strategies such as asking God for rewarding the favorer/wishing s.th good in utterances like:

69- Mersi aziz-am. Khoda kheir-et bede, kheili komakam kardi.

Thanks dear-my. God blessing- to you subj-give-3rd sing.

Very help-me did-2nd sing Thanks dear. God bless you, you helped me very much.

70- Dast-et dard nakone. Mersi

Hand-your sing pain doesn't. Thanks

May your hand never ache. Thanks

It is generally supposed that speakers in higher positions are capable of evaluating the performance of those of lower status, thus some speakers utilized compliments as positive reinforcements:

71- Dast-et dard nakone, mard-i shod-ia!

Hand-your sing pain doesn't. Man-a become-you

May your hand never ache. You have become a man!

72- Mersi, che pesare aqaei!

Thanks, what boy gentleman

Thanks, what a gentleman boy!

b. Persian learners of English

The responses of Persian EFL students in this situation were similar to their responses in situations 1 and 2. The use of intensifiers and qualifiers were quite obvious in these situations:

73- You really helped me. Thank you very much.

74- Thank you very much. I really appreciate you.

75- Thanks a million. I don't forget your favor.

In the last situation, many learners using one expression of gratitude, simply thanked their students for bringing them coffee.

76- Thank you very much.

77- Thanks a lot.

78- Oh, thank you.

c. American speakers

American students, on the other hand used simple thanking and complimenting in the fifth situation. Here the neighbour's son was appreciated by expressions like:

79- Thank you.

80- Thanks, it was great.

81- Hey man! Thank you very much.

In the last situation, as might be expected, all of the respondents employed simple thanking strategies including the more informal expression of cheers, to appreciate their students:

82- Oh, thanks.

83- Thanks.

84- Cheers.

\section{CONCLUSION}

The present study explored the gratitude expressions of native Persians, Persian learners of English in comparison with the data from native speakers of American English. The findings of the study showed that there are differences between the strategies that are employed for expressing gratitude in Persian and English languages.

As indicated in the table, the NAs did not change their strategy selections according to these variables frequently since they used simple thanking almost exclusively. The subjects of this group used considerable ratios of thanking + compliment or compliment only in situations 1,2 and 5 when the interlocutor belonged to the equal or lower social position and the received favor was of significant size of imposition.

Moreover, it was found that the PN speakers reacted more sensitively both to social status differences and to the size of imposition. While they changed their responses according to the size of imposition, a closer look revealed that they used more thanking expressions for a big favor (situations 1\&2) compared to situations representing small favor (situations $6 \& 7$ ).

English learners intended their responses to be polite but they were not appropriate to the social norms of American society. For example, their expressions for thanking their boss and thanking their neighbor's son were quit similar both in terms of strategy and in the number of expressions used. Generally it seemed that they were not equipped with 
appropriate tools to express gratitude according to the status of the interlocutor. Whereas Persian participants responded considerately to each social variable in their native language, in their foreign language it seemed that they didn't notice these variables and just reacted to the size of favor by adding intensifiers.

This suggests that it's not enough to build learners' linguistic competence and that it might be necessary to also develop their sociocultural competence, which will in turn, develop their understanding of the frames of interaction and rules of politeness within the target culture. It is also important to provide learners with knowledge of the linguistic forms or stylistic strategies appropriate to convey the intended meaning in different contexts or situations.

\section{APPENDIX A}

Age: Gender: malelfemale Education:

Please read the following situations in English and then their Persian translation. After reading each scenario write whatever you would naturally say in that situation in both versions (English and Persian). Say as much or as little as you feel appropriate for each situation. There may be situations in which you would say nothing, in such a case leave out the question. (Your interlocutor's gender is the same as yours).

1- You are having problems with a computer program your classmate has used this program for quite some time. You ask him/her to help you. He/she manages to solve the problem and show you how to avoid it in the future. What do you say?

2- You find yourself in sudden need of money $-\$ 500.00$. You mention this to a friend. Your friend immediately offers to lend it to you. You are surprised and very grateful. Your friend writes out a check for $\$ 500.00$ and gives it to you. At first you say, 'Oh no, I didn't mean for you to lend it to me. I couldn't take it.' Your friend says, 'Really, it's all right. What are friends for?' After your friend insists again, you take the check.

3- You work for a large company. The President of the company calls you into his office. He tells you to sit down. You feel a little nervous, because you have only been working there for six months. The President says, 'You're doing a good job. In fact, we are so pleased with you that I'm going to give you a \$20.00 a week raise.'

4- You ask your professor to write a recommendation letter because you need it for being employed in an institute. He accepts to write the letter and starts writing it willingly.

5- You are coming back from a trip. When you want to enter your apartment you see your neighbour's son who is a school boy. He helps you with your luggage and bags and brings them to your place.

6. At the table in a restaurant a friend says, 'You have something on your face.' You ask where. Your friend tells you. You rub your face and ask, 'Is it off?" Your friend says that it is.

7- You left your pen in a lecture. One of your classmates puts it into his/her bag and gives it back to you the following day before a seminar.

S/he: Here - this is yours, isn't it?

8- You were not able to attend the last seminar and have difficulties understanding one of the points of this seminar. After the seminar is over, you approach the lecturer, who has a very good relationship with all of his students. You tell him that you did not understand one of the points. He explains the point, when you want to leave,

9- You are carrying a lot of books into the university library. One of your professors who is coming out of the building keeps the door open for you. What do you say to the man/woman?

10- You tutor a school boy in English. After forty minutes you give him a short break and he brings you a cup of coffee.

\section{REFERENCES}

[1] Al-Falasi, H. (2007). Just say 'thank you': A study of compliment responses. The linguistic journal, 2 (1). Retrieved April 17, 2008, from www. Linguistics-journal.com

[2] Apte, M. L. (1974). 'Thank you' and South Asian Languages: A comparative sociolinguistic study. Linguistics, 136, 67-89.

[3] Bardovi-Harlig, K., \& Dörnyei, Z. (1997). Pragmatic awareness and instructed L2 learning: An empirical investigation. Paper presented at the AAAL 1997 Conference, Orlando.

[4] Blum-Kulka, S., \& Olshtain, E. (1984). Requests and apologies: A cross-cultural study of speech act realization patterns (CCSARP). Applied linguistics, 5, 196-213.

[5] Blum-Kulka, S., House, J., \& Kasper, G. (1989). Cross-cultural Pragmatics: Requests and Apologies. Norwood, New Jersey: Ablex.

[6] Bodman, J., \& Eisenstein, M. (1988). May God increase your bounty: The expressions of gratitude in English by native and non-native speakers. Cross currents, 15(1), 1-21.

[7] Brown, P., \& Levinson, S. (1987). Politeness: Some universals in language usage. Cambridge: Cambridge University Press.

[8] Cohen, A. (1996). Speech Acts. In S.L. McKay, \& N.H. Hornberger (Eds.), sociolinguistics and language teaching (pp. $383-$ 420). Cambridge: Cambridge University Press.

[9] Coulmas, F. (1981). 'Poison to your soul': Thanks and apologies contrastively viewed. In F, Coulmas, Conversational routine (pp. 69-91). The Hague: Mouton.

[10] Eisenstein, M., \& Bodman, J. (1986). 'I very appreciate': Expressions of gratitude by native and non-native speakers of American English. Applied linguistics, 7(2), 167-185.

[11] Eslami-Rasekh, Z., Eslami-Rasekh, A., \& Fattahi, A. (2004). The effect of explicit metapragmatic instruction on the speech act 
awareness of advanced EFL students. TESL-EJ, 8(2).

[12] Faerch, C. \& Kasper, G. (1987). Perspectives on language transfer. Applied linguistics, 8(2), 116-136.

[13] Ghobadi, A., Fahim, M. (2009). The effect of explicit teaching of English 'thanking formulas' on Iranian EFL intermediate level students at English language institutes. Science Direct, 37, 526-537.

[14] Janani,M. (1995). Pragmatic Failure of Iranian Language Learners in Expressing Gratitude. MA thesis. Tarbiat Modarres University. Tehran, Iran

[15] Kasper, G. (1989). Interactive procedures in interlanguage discourse. In W. Oleksy (Ed.), Contrastive Pragmatics. Amsterdam: Benjamins.

[16] Kasper, G. (1992). Pragmatic transfer. Second Language Research, 8 (3), 203-231.

[17] Miyake, K. (1994). 'Wabi' igaide tsukawareru wabi hyogen: Sono tayoukatno jittaito uchi, soto, yosono kankei ('Formulaic apologies in non-apologetic situations: A data analysis and its relation with the concept of uchi-soto-yoso'). Nihongo Kyouiku (Journal of Japanese Language Teaching), 82, 134-146.

[18] Murphy, B., \& Neu, J. (1996). My grade's too low: the speech act set of complaining. In S. Gass \& J. Neu (Eds.).

[19] Nakai, M., \& Watanabe, Y. (2000). A study on expressions of gratitude in Japanese and American English. Journal of Pan-Pacific Association of Applied Linguistics, 4(1), 200-216.

[20] Nakamura, K. (2005). Appreciation Strategies of German and Japanese Native Speakers and German Learners of Japanese. Proceedings of the 4th Annual JALT Pan-SIG Conference. May 14-15, 2005. Tokyo, Japan: Tokyo Keizai University

[21] Nakata, T. (1989). Hatsuwa koui to shiteno chinsha to kansha: Nichi-ei hikaku (Apology and thanks as speech acts: Comparison between Japanese and English). Nihongo Kyouiku, 68, 191-203.

[22] Olshtain, E. (1983). Socio-cultural competence and language transfer. The case of apology. In S. Gass \& L. Selinker (Eds.). Language Transfer in Language Learning. Rowley, MA: Newbury House Publishers.

[23] Olshtain, E. \& Blum-Kulka, S. (1985). Cross-cultural pragmatics and the testing of communicative competence. Language Testing, 2 (1), 16-30.

[24] Olshtain, E., \& Cohen, A. D. (1989). Speech act behaviour across languages. In H. Dechert \& M. Raupach (Eds.), Transfer in language production (pp.53-67). Norwood, NJ: Ablex.

[25] Searle, J. R. (1969), Speech Acts: An Essay in the Philosophy of Language. Cambridge: Cambridge University Press.

[26] Wolfson, N. (1989). The social dynamics of native and non-native variation in a complimenting. In M. Eisenstein (Ed).

[27] Yu, M. C. (1999). Universalistic and culture-specific perspectives on variation in the acquisition of pragmatic competence in a second language. Pragmatics, 9(2), 281-312

Vajiheh Ahar was born in 1984, Shiraz, Iran. She received her B.A in Teaching English as a foreign language from Shiraz University. In 2010 she received her M.A from Isfahan University, Iran. She has worked in the field of sociolinguistics and her thesis was a detailed contrastive pragmatic study of gratitude expressions in English and Persian and also in the interlanguage of Persian learners of English.

Abbas Eslami-Raskh is an assistant professor in Isfahan University, Iran. He received his B.A. in English Language, English Department of Isfahan University M.A. in Linguistics, English Department of Shiraz University Ph.D. in Linguistics, Department of Linguistics, Monash University, Australia. His research interests are issues related to intercultural pragmatics, interlanguage pragmatics, and sociocultural issues related to teaching ESL/EFL and he has published different articles in these fields. 